\title{
Perras, marginalidad y violencia en el teatro argentino del siglo XXI
}

\section{Rocío Zalba}

Perras (2002), trabajo colectivo de Néstor Caniglia, Enrique Federman, Mauricio Kartun y Claudio Martínez Bel, nos presenta la edificación de una entidad marginada en la nación argentina y su tendencia hacia la violencia y el engaño como forma de sobrevivir y resistir la condición que la separa y la atrapa. Sus personajes se presentan como productos de una Argentina post-crisis del 2001. En consecuencia, no reconocen su marginalidad y se desenvuelven tras una débil fachada de conversaciones cotidianas. Tal fachada los define, ya que se muestran inconscientes del efecto que han tenido sus pérdidas y se pierden bajo aquella ilusión de normalidad que pretenden vivir y con la cual esconden la violencia y perversión de sus actos, transformándose entonces en entidades indomables.

En este ensayo, propongo examinar cómo se representan en las tablas nacionales la identidad marginada, su edificación y su deconstrucción. A nivel constructivo, demostraré cómo los participantes se desenvuelven por medio de una nostalgia reflexiva, por la cual rememoran sus pérdidas y se identifican a base de sus ausencias. Es en esta suerte de contemplación que cada individuo busca el reconocimiento de su sufrimiento como también la posibilidad de poder establecer una relación con el otro. Sin embargo, la característica subversiva de estas entidades, junto al rasgo egocéntrico de una nostalgia que se caracteriza por su introspección, hace que la relación entre estos personajes se torne en un juego violento y deshumanizante. La concepción de supervivencia y ganancia individual ligada a la búsqueda del poder lleva al público a enfrentarse a una comunidad donde "el hombre es el lobo del hombre" y donde no se respetan los valores y morales que estructuran a la nación argentina. ${ }^{1}$ 
Defino márgenes, marginado o marginal como una entidad cuyo comportamiento, estilo de vida o condición física en escena se difiere y descarrila de la norma. Tal norma es caracterizada por lo que Michel Foucault nombra "la estética de la existencia", la cual está ligada al discurso moral del estado que sujeta al individuo a lo sano y lo enfermo, lo normal y lo patológico, lo bueno y lo malo (Historia 6-11). En esta obra teatral los marginados son los enfermos, patológicos y malos que residen en una zona intersticial o espacio liminoide, donde trascienden violentamente los límites de las convenciones sociales. ${ }^{2}$ La nostalgia reflexiva, por otro lado, en la que se desenvuelven los personajes de esta obra es descrita según Svetlana Boym en su estudio, The Future of Nostalgia, como una suerte de reflexión o meditación que origina de la memoria individual, más que colectiva, de la persona. ${ }^{3}$ Tal memoria personal es caracterizada por su fragmentación, su enfoque en el detalle y su habilidad en divagar por diferentes tiempos y espacios. Estas zonas tiempoespaciales pueden ser tanto reales como ficticias, lo cual alude al elemento lúdico de la nostalgia. Es justamente esta capacidad de explorar diferentes niveles de conciencia y realidades virtuales en la que la creatividad y el juego emergen de la nostalgia como otra forma de procesar las pérdidas. De hecho, Boym describe la nostalgia reflexiva de la siguiente manera: "Reflective nostalgia is a form of deep mourning that performs a labor of grief through pondering pain and through play, that points to the future" (54).

Mientras que Boym privilegia la nostalgia reflexiva por ser una que mira hacia el futuro, en este ensayo propongo examinar el poder destructivo de esta nostalgia cuando es acogida por seres marginados que se construyen y destruyen en los bordes de la condición humana. La condición humana a la que me refiero es aquella que refleja una Argentina profundamente erosionada, la cual a finales del siglo XX y principios del siglo XXI se caracteriza por su clima hostil de corrupción, violencia y desconcierto. Uno de los cambios más evidentes en la última década del siglo XX, el cual ha provocado una modificación en el modo en que el ser argentino se relaciona con los demás, es el auge de la corrupción. De hecho, el tema principal en las elecciones presidenciales de octubre de 1999 fue el aumento de violencia e inseguridad, especialmente en las zonas urbanas. Según Mempo Giardinelli, el argentino medio vive en un constante estado de inseguridad y desconfianza de todo y todos. Ni las instituciones de seguridad y justicia se salvan de ser temidas por el pueblo. El respeto no existe por nada ni nadie (361). ${ }^{4}$ Beatriz Sarlo no atribuye este auge de violencia, desconfianza e inseguridad ni a la pobreza ni al incremento del desempleo sino a "la cultura desagregada que se produce 
en un medio donde el horizonte de expectativa es precario" (60), es decir, la inhabilidad del Estado en otorgarle a la gente la seguridad que le garantiza. Consecuentemente, el pueblo se ha dividido y la gente se ha aislado para tratar de sobrevivir. Es así como, según Roberto Kozulj, el país a fines de siglo es caracterizado por un individualismo extremo como también un alto grado de aversión hacia la incertidumbre, la inseguridad y el futuro (1). Comprendemos, por lo tanto, la alusión que hace Giardinelli cuando retrata al pueblo argentino al fin del milenio como "civilizada barbarie" para luego concluir con la siguiente frase: "Siempre el lobo del hombre fue el hombre, pero nunca el hombre fue tan lobo como en este fin de milenio" (364).

La trama en Perras es singular. Dos desconocidos y sus respectivas perras se encuentran en la oscuridad de la noche en un parque urbano. Las perras son invisibles al ojo del espectador; sólo se materializan por medio de las acciones y expresiones verbales que sus dueños tienen con ellas. El diálogo entre los desconocidos se basa mayoritariamente en tratar de convencer al otro sobre cómo cuidar a su animal. Néstor es el dueño de Yanina y ama a su perra como si fuera su engendro. La humaniza en su cuidado meticuloso de comida, limpieza, ejercicio y amaestramiento. Claudio es su opuesto. Éste trata a su perra Colita de una forma abusiva y violenta. La maltrata y la engaña tanto en el juego como en su cuidado. Dentro de sus discusiones los hombres comparten también datos personales y memorias pasadas. Néstor se ha divorciado de su esposa, mientras que la novia de Claudio se ha suicidado. Es tras una nostalgia contemplativa, por la cual comparten sus memorias personales, que el público reconoce a Claudio como el prototipo del hombre abusivo y violento dentro del espacio doméstico. Néstor, por otro lado, se distingue por practicar el bestialismo con su perra. El descubrimiento en cuanto la brutalidad de estos hombres es lo que explica los combos lúdicos que se entremeten en los diálogos. En estos combos, que no pertenecen a un tiempo o espacio específico, los hombres van de jugar en unísono con sus perras a convertirse ellos mismos en bestias que se desafían agresivamente al final de la obra. He aquí la animalización de entidades que infringen con violencia los márgenes sociales y que hacen de la frase "el hombre es el lobo del hombre" un retrato literal. ${ }^{5}$

Como ya he mencionado, Perras fue escrita tras la crisis del 2001, época en que Argentina padeció la peor crisis económica, política y social de su historia reciente. Existe en este período un fuerte aumento en los casos de delincuencia violenta, robos y secuestros. Nadie está a salvo. Esta agresión lleva a que se acrecienten las tensiones sociales, lo que crea una 
fuerza centrífuga en la sociedad donde los individuos se separan en grupos o individualmente en busca de refugio. Aquellas entidades que ya residían en los márgenes son expulsadas aun más dentro de estos espacios liminoides, sitios donde la estructura convencional no existe y donde pueden resistir las reglas socio-culturales con las que no se identifican (Turner 53). Es dentro de estos espacios laterales que el público observa cómo la representación de las identidades marginales en Perras retrata el doble efecto de esa fuerza centrífuga. Digo doble, porque por un lado la expulsión hacia los márgenes logra construir una identidad por medio de sus ausencias y sufrimientos, mientras que por otro lado debe separarse con el propósito de sobrevivir las amenazas y dificultades de ese espacio en que se vive salvajemente.

La marginación de los protagonistas en Perras no se debe a una discapacidad física sino a una mentalidad patológica. Esto significa que es más difícil discernir a primera vista la condición marginal de los personajes. En esta obra, son los pensamientos y las acciones de los protagonistas lo que los separa de la norma. Néstor practica la bestialidad con su perra mientras que Claudio es violento y agresivo con su perra y novia. Sin embargo, tales actores no parecen estar conscientes de aquellos rasgos que los marginalizan. Lo que es peor, se desenvuelven tras una fachada de conversaciones cotidianas donde se penetran en el engaño de su existencia. Tal existencia se define por la relación que cada uno tiene con sus respectivas perras. Es tras la especificidad en la relación de dueño / mascota que podemos observar cómo cada personaje encubre, inconscientemente, no sólo la condición que lo ha empujado hacia los bordes, sino las ausencias y pérdidas que ha sufrido a base de su condición marginal. Es así como la relación con lo que poseen—sus perras - es a su vez lo que revela sus pérdidas y ausencias.

La ausencia principal que define a ambos protagonistas es la pérdida de una mujer. A través del diálogo sabemos que la novia de Claudio se ha suicidado y que la esposa de Néstor se ha divorciado de él. A nivel teatral, estas pérdidas se materializan con la ausencia misma de estas perras sobre el escenario. Después de todo, el dramaturgo podría haber dado el papel de canina a otros dos actores. Sin embargo, es la invisibilidad de estas mascotas sobre el escenario lo que le exige al espectador crear un vínculo entre la ausencia física de la mascota y la mujer. Aún más, lo incorpóreo de estas "perras" sobre el escenario hace que toda la atención recaiga sobre el protagonismo de Néstor y Claudio, lo cual magnifica la "animalización" de estos individuos en el transcurso del performance. Por último, al sólo tener el victimario sobre el escenario, el público puede mejor absorber la gravedad 
de sus comportamientos marginales sin tener que simpatizar con las víctimas; esto último asiste a que percibamos a Néstor y Claudio tanto como agresores y víctimas de una comunidad deteriorada.

Es a través de la relación que los protagonistas tienen con sus respectivas perras junto con su forma de rememorar la relación pasada con sus esposas que demuestra cómo las perras han tomado el lugar de estas últimas. Durante la obra apreciamos cómo Néstor humaniza a su perra Yanina a través del habla y del juego. Su delicadeza con ella en ocasiones se equipara a la de un hombre con su pareja: "No me mirés así... Si te digo vení, venís (Una palmada en el muslo. Ella le lame la mano. Intenta infructuosamente sostener su enojo) Despacio... No. Ahora no. Estoy enojado. No me mirés así" (117). En otras ocasiones actúa como un padre con su hijo: “¿Querés hacer popó? ¿Y por qué no me pedís?... Sí, acá está bien. ¡Muy bien!... ¡Cuánta cacona!... Bueno, ahora quédate quietita... eso... muy bien... esperá. (Le limpia el culo con su propio pañuelo)" (122). Si unimos esta clara humanización a los comentarios que el protagonista hace sobre su ex esposa, comprendemos que existe un lazo estrecho entre ambas. Por ejemplo, a Néstor le gustaría que Yanina aprendiera diferentes idiomas, lo que se compara a su esposa, Suzy, que es profesora de inglés. Otro ejemplo, quizás el más sutil y severo, se presenta cuando saca a relucir la disconformidad de Suzy en sus relaciones sexuales. Según Nestor, su esposa se quejaba con frecuencia de su vida sexual, "Que tendrías que esto, que tendrías que lo otro, que así no, que más despacito. Y eso que Susy, ojo... Pero ya es su naturaleza" (121). Tal comentario se liga directamente con la última escena de la obra donde el público se sorprende al ver el protagonista tener sexo con su perra, la cual no se queja ni resiste. Este último ejemplo, junto con otras críticas que hace Néstor de su mujer, revela que el protagonista ha logrado a través de un papel dominante con Yanina la satisfacción que no obtuvo con su esposa. Por consiguiente, las acciones que lleva a cabo con este animal se asemejan o se contraponen a la relación que tenía con su ex-mujer. Sea cual fuera el acercamiento, la posesión y el contacto que tiene con la entidad canina no dejan de señalar su pérdida.

Mientras que Néstor es dulce, Claudio es abusivo y descuidado con su perra Colita. Varias veces la engaña: "(Con un palo que ofrece a Colita. Amaga tirárselo pero se lo esconde detrás.) ¡Busca! ¡Busca! ¿Dónde está...? Acá está... ¡Sos tarada, eh!” (122). Otras veces le pega con furia y violencia: "Te la estás buscando, eh... Ves que sos vos la que te la estás buscando... ¡Soltá...! (Estalla. Le pega con la correa con brutalidad desmedida.) ¡Ves lo que me hacés hacer!" (122). Estas reacciones son casi idénticas a las que tenía 
con su novia antes de que ésta se suicidara. Es en una escena cuando Claudio rememora su enojo hacia su novia que el público presencia el paralelismo entre ambas: "¡Qué carajo te pasa! ¡Te volviste loca! ¡Desde cuándo una perra de mierda es más importante que yo...! ¡La puta madre que te parió...! ¡Ves que sos vos que te hacés pegar...! [...] (Estalla. Le pega con la correa como a Colita.)" (129). Esta semejanza y continuidad en comportamiento y palabras exhibe cómo Colita ha tomado el lugar de su novia, lo que a su vez devela la ausencia de esta última.

Pero no es sólo la relación personal de cada dueño con su perra lo que hace que la posesión revele su pérdida, sino la forma en que hablan sobre ellas. En más de un diálogo se torna difícil para el espectador discernir si están hablando de sus mujeres o de sus perras:

NÉSTOR. Si uno pudiera saber lo que están pensando, ¿no?...

CLAUDIO. Quién las entiende...

$[\ldots]$

NÉSTOR. Hay que agarrarlas de chiquitas y hacerlas a tu manera. (Claudio coincide.) Lo importante es que se sientan que el que manda es uno.

CLAUDIO. Ahí, sí... Si te ven débil, te pasaron por encima. (128)

Otro ejemplo es cuando ambos protagonistas acuerdan que todas las mujeres son iguales, palabras que luego vuelven a reiterar en la última escena de la obra cuando hablan de sus dos perras:

CLAUDIO. Qué cosa, ¿no?, una chiquita y la otra tan grande pero juntas no hay diferencia...

NÉSTOR. Es que cuando las empezás a descubrir te das cuenta que son todas iguales...

CLAUDIO. Todas iguales...

NÉSTOR. Son todas iguales... (131)

Consecuentemente, en la obra la perra no sólo suplanta a la mujer sino que es sinónimo de ésta, una alegoría peyorativa que nos revela la condición deshumanizante del hombre argentino a principios de siglo XXI. En esta representación teatral, no existe diferencia entre la relación con un animal y la relación con un humano, entre una posesión y una pérdida.

Relacionarse con sus perras es para ambos hombres una forma de encubrir y a su vez señalar un vacío. Tal vacío, como ya he mencionado, es retratado teatralmente por la ausencia física de actores que ejecuten el papel de perras sobre el escenario. A nivel psicológico, sin embargo, tal ausencia puede ser explicada por las teorías de María Vaca Guzmán, quien indica que 
hay una clara conexión entre la crueldad hacia los animales y la violencia interpersonal. Según Guzmán, tal correlación señala la semejanza sentimental que existe entre un hombre y un humano, y un hombre y un animal. Es así como tal correspondencia implica que el contacto de ambos personajes con sus perras es el primer indicio de una nostalgia reflexiva. Después de todo, sabemos que la nostalgia puede desplegarse en una multitud de posibilidades, siendo una de ellas la imposición del pasado en sentimientos y actos del presente. Según las teorías de Boym, "the past might act and will act by inserting itself into a present sensation from which it borrows vitality" (50). En la obra, la acción de cada dueño con su perra parece estar influenciada justamente por sus memorias pasadas. En sí, el intercambio con sus caninas es un contacto presente que se asemeja, o se contrapone en algunos casos con Néstor, a sus relaciones amorosas en el pretérito. Por consiguiente, el comportamiento de ambos protagonistas está manchado de una nostalgia que procesa la pérdida a través de una relación personal e intensa con lo que poseen.

Mientras que la posesión y la relación con sus perras encubren y revelan la soledad de estos hombres, la forma violenta y abusiva en que se manejan con sus perras señala otras pérdidas como la falta de auto-estima y la ausencia de poder. La inestabilidad en la auto-percepción de los personajes es un desequilibrio que se revela en el momento que recordamos la jerarquía de seres racionales donde el hombre ocupa un nivel superior en el reino animal. Según Guzmán, cuando el hombre maltrata al animal delata una inseguridad interna. Aun más, argumenta que el acto violento revela en el hombre "un esfuerzo para compensar por sentimientos de inferioridad y falta de poder". Si consideramos la forma en que concluyeron las relaciones amorosas de Néstor y Claudio con sus respectivas mujeres, entonces podemos asumir que tales sentimientos de inferioridad caracterizan perfectamente a ambos personajes. La esposa de Néstor, por ejemplo, tiene otra pareja, lo cual indica que, entre los dos, ha sido ella la que ha podido progresar y salir adelante. El suicidio de la novia de Claudio, por otro lado, puede ser visto, según las teorías de Michel Foucault en "Right of Death", como una manifestación de oposición hacia aquel que trata de gobernarlo todo. Según el teórico, el suicidio "testifies to the individual and private right to die, at the borders and in the interstices of power that is exercised over life" (261). Por consiguiente, la auto-destrucción de Pato, su novia, puede ser visto como un acto de rebeldía contra su novio abusivo y así reflejar una manifestación de poder que desafía una vida que desilusiona y oprime. 
A pesar del rasgo de inferioridad que enmarca a ambos personajes, su falta de concientización hacia la condición patológica que los marginaliza ayuda a fomentar una falacia de poder y control que exhiben sobre sus animales. Esta relación es la que les devuelve la posición machista, masculina o dominante que perdieron (¿o nunca tuvieron?) con sus compañeras. He aquí la falsa ilusión y percepción en la que viven los protagonistas, la cual se asemeja de una forma perversa a la sociedad argentina, caracterizada en las últimas décadas por una violencia que busca poder dentro de la desilusión y sentimiento de desventaja en la que vive. En un editorial escrito para el diario Clarín, titulado "Marginados y violencia social", el autor argumenta que la inestabilidad en la sociedad argentina se debe en parte a la ignorancia del Estado al no enlazar el aumento de violencia y corrupción a finales del siglo XX con aquellos marginados que responden "a la violencia de un orden que los ha expulsado". Tal violencia por parte del marginado puede ser tanto una agresión física como una ruptura de las leyes o un desafío a los valores morales de la sociedad. Sea cual fuera, según el autor, todos se caracterizan por su resistencia y por querer ser, por querer sobrevivir, por querer adquirir aquel poder y voz que se les fueron despojados en el momento en que los marginados fueron definidos como defectuosos y empujados hacia los bordes.

Los personajes en Perras no sólo se construyen y definen a base de sus pérdidas, sino también en el intercambio que establecen con su interlocutor. Esta identidad como "otro" se fortalece y se sella con el reconocimiento de su propio sufrimiento y las ausencias en su vida. Es hacia finales de la obra que tanto Claudio como Néstor se pierden en un clima de ensoñación, en el que vuelven a revivir a través de una nostalgia reflexiva aquellos actos que señalan la pérdida de su compañera y que los ubica en los márgenes en que se encuentran. Es junto con un cambio de luz que Claudio vuelve a revivir el momento donde la violencia hacia su novia la lleva al suicidio. En esta escena Néstor toma el papel de Colita y aúlla: "Un cambio de luz introduce lentamente un clima de ensoñación. Claudio recuerda. El departamento de Pato el día aquel. Néstor a un lado ladra y aúlla como Colita aquella noche" (129). Lo mismo vuelve a ocurrir pero esta vez siendo Claudio el que se penetra en el recuerdo de Néstor, tomando el papel de Yanina:

Casa de Néstor. Este de espalda cepilla amorosamente a Yanina. Una caricia sensual, equívoca [...] Crece su excitación. Se perciben movimientos con los que Néstor intenta acomodarla de espaldas a él. Lo consigue. La penetra. Claudio, a un lado, aúlla como ella cada vez. (130) 
La participación de cada uno en el recuerdo del otro demuestra hasta qué punto su interacción los ha llevado en la edificación de una identidad que se basa en la complicidad y comprensión de su interlocutor. En el momento en que Néstor y Claudio toman el papel de la perra, están penetrándose en la nostalgia reflexiva de su compañero y así adquiriendo el lugar de aquello que simboliza la posesión que encubre la pérdida de su interlocutor. La participación en esta memoria, por lo tanto, es una forma de establecer una cercanía e intimidad entre los personajes. También resalta la identificación no sólo con aquella fachada que, como una máscara, esconde su sufrimiento, sino también con el acto ilícito y marginal que ambos ejecutan. Es decir, en el momento en que Claudio participa en la bestialidad que ejecuta su compañero y Néstor aúlla al ver la violencia de Claudio, entonces no sólo son cómplices sino entidades activas y performativas que condonan, comprenden y asimilan la perversidad del otro. La brutalidad de estas escenas se debe, nuevamente, a la falta de reconocimiento de ambos protagonistas en cuanto a la anormalidad de sus actos, lo que los penetra aun más en la marginalidad en la que se encuentran. Consecuentemente, tal inclusión onírica que permite aquel estado nostálgico es lo que termina definiendo la construcción de estas identidades marginales.

Según las teorías de Boym, la colectividad que surge de diferentes individuos origina de aquellas memorias individuales que se desplazan en espacios comunes. A este argumento añade que la colectividad de tal memoria ofrece una zona de estabilidad y normalidad para el nostálgico que reside en tiempos modernos de cambio (53). Ya que Néstor y Claudio son entidades marginales que se encuentran tanto física como mentalmente en un espacio oscuro y ambiguo, el compartir sus memorias les ha otorgado una solidez y compañerismo en su identidad que fortalece su posición en los márgenes. Por consiguiente, es en los bordes que ambos protagonistas se desenvuelven tras una concientización nostálgica, por la cual se identifican y construyen.

La identidad colectiva en Perras se establece no sólo por medio de una nostalgia reflexiva por la cual los personajes rememoran y entran en contacto con su pasado sino también a través de la característica lúdica que ésta ofrece. De hecho, esa característica de creatividad y libertad define la nostalgia y permite que ambos personajes entren en una suerte de juego donde procesan sus pérdidas por medio de una ficción. Es entre los diálogos cuando Néstor y Claudio tratan de (con)vencer al otro sobre su forma de amaestrar y cuidar a sus perras que se intercalan tres combos donde los protagonistas entran en un recreo idílico con sus animales. Estos juegos son establecidos a nivel teatral con un cambio de luces y colores sobre el escenario. El 
propósito de estas técnicas luminarias es crear un ambiente surreal, lejos de todo "naturalismo" (120). Combo $2^{\circ}$ por ejemplo se describe de la siguiente forma: "Una coreografia de movimientos ahora, de los hombres jugando con sus perras y los palos. Arrojan, reciben, esquivan y concluyen retándolas a coro con un: ¡Cheee!” (122). Combo $3^{\circ}$ comienza así: “Comienzan a llamar a sus mascotas. Una antología de lugares comunes: silbidos, chasquidos, palmadas y gritos que van instalando un ritmo común e inevitable" (126). Según Ana Duran en su reseña de la obra, los combos se presentan como "cierre o gags de algunas escenas que de otra manera hubieran caído en la declamación". Sin embargo, esta suerte de interrupciones lúdicas dentro de las conversaciones puede ser vista, según las teorías de Johan Huizinga en su estudio sobre el juego, como un intermezzo. El intermezzo es el propósito del juego en su forma más básica, es decir, una actividad que interrumpe la vida cotidiana como forma de recreo y para recrear. Si consideramos que la nostalgia reflexiva les permite a los personajes una divagación de tiempos y espacios en la cual pueden explorar lo que pudo haber sido o nunca fue, entonces la re-creación del juego es indicativa cuando examinamos el comportamiento bucólico de los personajes con sus perras. Es en estos combos que el público observa cómo Claudio y Néstor dejan a un costado aquellos rasgos de extrema violencia y abuso hacia sus perras, para jugar de una forma sana, pintoresca y hasta pastoral con ellas. Considerando que las perras son aquella posesión que señala la ausencia femenina, entonces este juego saludable es una suerte de performance que les permite tener un contacto enriquecedor y poco doloroso con aquello que perdieron. Sus actos dentro de este espacio surreal manifiestan frente al espectador lo que podría haber sido y nunca fue.

Es revelador y no coincidente que este contacto saludable y juguetón de los personajes con las perras sólo ocurra en espacios "surreales" o, en otras palabras, inexistentes ante la mirada del público. Esto significa que la realidad social que refleja esta obra es la de una débil fachada que esconde la inconciencia o falta de reflexión hacia la violencia doméstica y la bestialidad en Argentina. Según Guzmán, "no existe en la Argentina una fuerte conciencia social acerca del maltrato animal". Tal inconciencia puede llevarse también al hogar o núcleo familiar. De hecho, Giardinelli indica que el argentino se conduce en su familia con cierta impunidad, la cual se presenta en la vida diaria como justificación de la violencia doméstica. Aun más, considera que el elemento clave que hace estos actos permisibles es el pensamiento que "en la intimidad del hogar y de la familia vale todo y nada debe trascender" (372). Lamentablemente, y como indica el teórico, la conducta individual 
determina la conducta colectiva. Por ende, es justamente lo trascendente de esta violencia individual lo que causa que el país esté acorralado por una emergencia de entidades agresivas que se manifiestan tanto en el espacio privado como público a principios del siglo XXI.

Mientras que el elemento lúdico de la nostalgia reflexiva les permite a los personajes la oportunidad de alterar su presente o pasado con el propósito de explorar lo que fue, podría haber sido o puede ser, el elemento competitivo del juego crea rivalidad entre los miembros, quienes hacen uso y abuso de su condición marginal. Es en el último combo que el público observa cómo la ficción se penetra en la conversación de los personajes y su realidad. Luego de participar en la memoria del otro, Claudio y Néstor se transforman en dos perros feroces dentro de la plaza: "Ambos se agachan intentando tomar un palo del piso. Eligen el mismo. Forcejean. Luchan por él. Entablan una batalla feroz. Se muerden, aúllan, gruñen" (130). Tal trasgresión del juego a la realidad es lo que termina provocando una violencia intensa entre estos personajes ya que, como animales, se pelean por establecer dominio sobre el otro y así ejercer aquel poder y control que carecen. He aquí la destrucción de estos personajes, los cuales revelan finalmente la fantasía en la que vivían cuando su edificación se basaba en conversaciones banales sobre mascotas, escondiendo así la perversidad de sus actos destructores en su vida personal.

Ahora bien, tomando en cuenta que Yanina y Colita toman el lugar de las mujeres de Néstor y Claudio, es comprensible que dentro del juego los mismos protagonistas se tornen en lo que su verdadero comportamiento revela - perros, animales salvajes e inferiores al hombre, según la jerarquía convencional. He aquí cómo la frase "el hombre es el lobo del hombre" se manifiesta literalmente, lo que sugiere cómo la violencia lleva a la deshumanización del hombre, lo cual caracteriza aquella violencia gratuita vista a finales del 2001 y en el 2002 que destruye la comunidad establecida sin ningún tipo de solidaridad y humanidad.

La rivalidad en la comunidad de Perras se debe a la incapacidad de los personajes de reconocer la realidad marginal en la que viven y, por lo tanto, residen en una ilusión que los junta y luego los destruye. Por ende, los personajes se distancian de esta realidad, creando un mundo paralelo donde sus perras son la posesión que encubre una serie de pérdidas. Como un espejo deformante, tales identidades marginales nos comunican cómo el argentino se identifica y desidentifica con el otro por medio de una nostalgia reflexiva donde la división entre la realidad y la ficción es ambigua. También nos demuestran que lo único que vale a finales de siglo es sobrevivir a través de 
la adquisición del poder. Aun más, la obra nos revela cómo la supervivencia se basa en una resistencia que se caracteriza por medio de distanciamiento, exclusión, engaño y violencia. Tal caracterización no sólo enmarca la obra en este ensayo, sino también toda una dramaturgia escrita a finales del siglo XX y principios del siglo XXI, cuyo propósito es comunicar a través de imágenes agresivas y desconcertantes las tensiones identitarias que definen a la nación.

\section{Columbia College}

\section{Notas}

1 "El hombre es el lobo del hombre" ("Homo Homini Lupus") es un proverbio popular romano, creado por el comediógrafo latino Tio Marcio Plauto (254adC- $184 \mathrm{adC}$ ) y presentado en su comedia Asinaria.

2 El término liminoide elaborado por Victor Turner en su estudio From Ritual to Theatre: The Human Seriousness of Play es descrito como un espacio donde se ejecutan actividades que desafían las estructuras convencionales, a través del juego, del azar o de una actitud subversiva. En este espacio hay una concentración en el desarrollo de la persona o grupo que se manifiesta fuera de los procesos centrales, económicos y políticos. En su desenvolvimiento sobre los márgenes, existe una necesidad de competir para ser reconocido por medio de actividades lúdicas (53-55).

3 En su libro, Boym habla sobre dos tipos de nostalgia a los que llama la nostalgia restaurativa y la reflexiva. La primera, según la escritora, se define como la reconstrucción de las pérdidas desde sus orígenes. Aquí el nostálgico busca regresar al hogar, los mitos y los símbolos religiosos o nacionales del pasado como si fueran verdades absolutas. No es una nostalgia muy fructuosa, ya que no se ve a sí misma como una nostalgia. La nostalgia reflexiva, por otro lado, es la que examino y describo en mi estudio.

4 Mientras que reconozco que los actos de terror y el disturbio formaron gran parte de las décadas de los sesenta y setenta, la violencia y la corrupción de los años noventa se difiere en que los actuantes componen parte de la esfera pública, al opuesto de ser un terror organizado y dirigido por aquellos en poder. Tampoco hay necesariamente una agenda política tras los actos de agresión. El desorden violento, por lo tanto, se presenta como síntoma y reacción de la inestabilidad económica y social que produce el gobierno menemista.

5 Es imposible leer esta obra y no reconocer o recordar la obra de Osvaldo Dragún El hombre que se convirtió en perro (1957). Mientras que en Perras la metamorfosis es inconsciente y producto de una sociedad violenta e indomable, en la obra de Dragún el hombre escoge trabajar como perro al no poder conseguir empleo humano. Este nuevo oficio lo hace a cambio de casa, comida y veterinario para poder sostener a su familia. De una forma similar, ambas obras reflejan el contorno social que produce la animalización del hombre. Sin embargo, en Perras la deshumanización retrata la violencia y desconcierto de la post-crisis del 2001, mientras que en la obra de Dragún es la alta tasa de desocupación en una Argentina de los años cincuenta y sesenta lo que hace que alguien caiga tentado ante una propuesta humillante. 


\section{Bibliografía}

Boym, Svetlana. The Future of Nostalgia. New York: Basic Books, 2001. Impreso. Caniglia, Néstor et al. Perras. Teatro argentino. Introd. Jorge Dubatti. Buenos Aires: Libros de Tierra Firme, 2000. 115-31. Impreso.

Duran, Ana. "Tu Perro, Tu Caca". Crítica de la Revista 3 PUNTOS. 24 de febrero de 2002. Web. Abril de 2013.<http://www.actors-studio.org/joomla/index.php/ component/k2/item/86-critica-de-la-revista-3-puntos-24042002>

Foucault, Michel. Historia de la sexualidad Vol II. El uso de los placeres. México: Siglo Veintiuno Editores, 1977. Impreso.

. "Right of Death and Power over Life". The Foucault Reader. Ed. Paul Rabinow. New York: Pantheon Books, 1984. 258-72. Impreso.

Giardinelli, Mempo. El país de las maravillas. Los argentinos en el fin del milenio. Buenos Aires: Planeta, 1998. Impreso.

Guzmán, María Vaca. "Violencia y maltrato a los animales: Estudio de casos en Argentina”. Fundación Argentina de Bienestar Animal. Mayo 2004. Web. Febrero 2007. <http://www.fabaonline.com/faba_live/ampliar. $\mathrm{html}$ ?action=ampliar\&record_id=104\&nombre_seccion=INTERES_GENERAL $>$.

Huizinga, Johan. Homo Ludens. Trad. Eugenio Imaz. Buenos Aires: Emecé Editorial, 1968. Impreso.

Kozulj, Roberto. "Argentina: un país que no se reconoce racista, que no afronta sus contradicciones". BACYAM. Febrero 2007. Web. <http:www.bacyam.com. ar/contribuciones $2 /$ kozulj1.doc $>$.

"Marginados y Violencia Social". Clarín Digital. 14 de mayo de 1997. Web. Febrero 2007. <http://www.clarin.com/diario/1997/05/14/00editor.htm>.

Sarlo, Beatriz. Tiempo presente. Notas sobre el cambio de una cultura. Buenos Aires: Editorial Veintiuno Editores Argentina, 2001. Impreso.

Turner, Victor. From Ritual to Theatre: The Human Seriousness of Play. New York: Performing Arts Journal Publications, 1982. Impreso. 